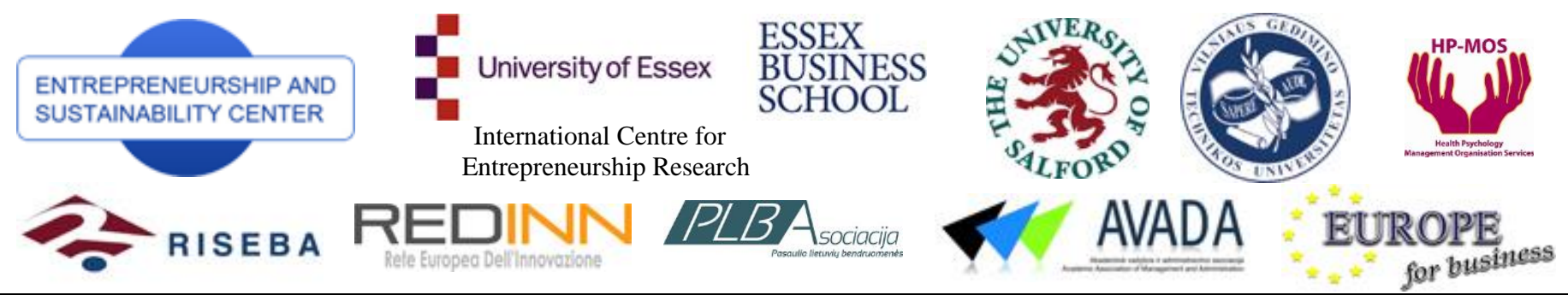

ENTREPRENEURSHIP AND SUSTAINABILITY ISSUES

ISSN 2345-0282 (online) http://jssidoi.org/jesi/

\title{
TOWARDS SMARTER AND MORE SUSTAINABLE CITIES: THE REMOURBAN MODEL ${ }^{1}$
}

\author{
Miguel Á. García-Fuentes ${ }^{1}$, Cristina de Torre ${ }^{2}$ \\ ${ }^{1,2}$ Fundación CARTIF, Parque Tecnológico de Boecillo 205, Valladolid, Spain \\ E-mails: ${ }^{1}$ miggar@cartif.es; ${ }^{2}$ critor@cartif.es
}

Received 15 October 2016; accepted 10 December 2016

\begin{abstract}
REMOURBAN is an European project whose main objective is the development and validation in three lighthouse cities (Valladolid-Spain, Nottingham-UK and Tepebasi/Eskisehir-Turkey) of a sustainable urban regeneration model that leverages the convergence area of the energy, mobility and ICT sectors in order to accelerate the deployment of innovative technologies, organizational and economic solutions to significantly increase resource and energy efficiency, improve the sustainability of urban transport and drastically reduce greenhouse gas emissions in urban areas.

For developing this model, REMOURBAN is implementing several strategies at city level based on: the creation of a holistic catalogue of innovative technologies and solutions on energy, mobility and ICTs favouring the replicability, the identification and overcome of nontechnical barriers, the development of new integrated business models oriented at the creation of a European market for innovation and the definition of a complete evaluation procedure using sustainability and smartness indicators.

This urban renovation strategy is focused on the citizens, where they become the cornerstones to making a smart city a reality For this reason, citizens are being actively engaged in REMOURBAN and the population awareness about energy and environmental impact of their daily activities are increased.

In order to ensure the usefulness and high replication of the REMOURBAN project at European level, the sustainable urban regeneration model is aimed at the decision makers, investors, public administrations and the industrial sector. Furthermore, in order to ensure this replicability, two follower cities, Seraing (Belgium) and Miskolc (Hungary) are involved in the project so they can apply the developed model once it is validated. The project will allow demonstrating that, by means of improving the current conditions of a city, it is possible to achieve low energy districts and more sustainable urban transport, as well as to perceive a greater quality of life. REMOURBAN, thus, will focus on improving the energy efficiency, reduction of GHG emissions, refurbishment of districts, transport sustainability, access to urban information and citizen engagement.

A big impact across Europe is intended to be achieved by the REMOURBAN project results at European level, showing the model for sustainable urban regeneration can be easily applied and replicated. With the aim at maximizing the impact of the project results,
\end{abstract}

This research was supported by the project, which has received funding from the European Union's Horizon 2020 research and innovation programme under the grant agreement No 646511.

The article reflects the views only of the authors, and the Commission cannot be held responsible for any use which may be made of the information contained therein. The information in this document is provided as is and no guarantee or warranty is given that the information is fit for any particular purpose. The user thereof uses the information at its sole risk and liability 
REMOURBAN is deploying a powerful communication and dissemination plan that integrates a citizen engagement strategy and has started to disseminate the benefits of the project to a wide variety of audiences.

Keywords: Smart city, regeneration, replicability, energy efficiency, mobility

Reference to this paper should be made as follows: García-Fuentes, M.Á., De Torre, C. 2017. Towards smarter and more sustainable regenerative cities: the REMOURBAN model, Entrepreneurship and Sustainability Issues, 4(3): 328- 338. http://dx.doi.org/10.9770/jesi.2017.4.3S(8)

JEL Classifications R11, R41, R51

Additional disciplines: urban planning, architecture, environmental engineering.

\section{Introduction}

REMOURBAN is a large-scale demonstration project, whose purpose is to accelerate the urban transformation towards the smart city concept taking into account all aspects of sustainability. Energy, transport and ICT sectors are essential for the day-to-day of the city. These sectors are widely considered as potentially appropriate to achieve economic and societal benefits, becoming a key towards improving the quality of life of the citizens, and representing most of the interrelations between people and technology. A big challenge to offer new interdisciplinary opportunities to strengthen the potential to become smarter and more sustainable cities is still open in the common area where energy production, distribution and use; mobility and transport; and information and communication technologies work together.

To deal with these challenges, Sustainable Urban Regeneration Models are needed, defining an integrated and holistic process to transform the city ecosystem with a jointly focus in the fields of sustainable buildings and districts, sustainable urban mobility, and integrated infrastructures and processes. This is where REMOURBAN is working to provide a replicable model which delivers solutions in both technical and non-technical related fields addressing the temporal goals, the main Smart City enablers within the transformation process -towards a more sustainable and smarter environment-, and innovations in the priority actions of energy, mobility and ICTs.

This urban regeneration model will be developed and validated in three lighthouse cities (Valladolid-Spain, Nottingham-UK and Tepebasi/Eskisehir-Turkey) accelerating the deployment of innovative technologies, organisational and economic solutions to significantly increase resource and energy efficiency, improve the sustainability of urban transport and drastically reduce greenhouse gas emissions.

Besides the lighthouse cities, two cities are involved in the project with the role of follower, Seraing in Belgium and Miskolc in Hungary. These cities allow increasing the European dimension of the project and its replication potential. In order to achieve this objective, a methodology for the replication of this urban regeneration model is being developed from the three main lighthouses to the follower cities and from there, to any other city in Europe, as a holistic strategy for city transformation and planning, integrating all the existing strategies for energy, mobility, ICTs and citizen engagement.

\section{An Integrated Urban Regeneration Model}

The main goal in REMOURBAN is to provide a Sustainable Urban Regeneration Model that defines a holistic process for urban transformation with a jointly approach in the fields of Sustainable Buildings and Districts, Sustainable Urban Mobility, and Integrated Infrastructures and Process. This model provides solutions in both technical and non-technical fields addressing the temporal goals, the main Smart City enablers within the transformation process - towards a more sustainable and smarter environment- and innovations in the priority 
actions of energy, mobility and ICTs. The Urban Regeneration model covers the four main phases of the city transformation process, which are linked to the specific actions and the Smart City enablers, being:

- City audit is the first phase of this model, aiming at implementing a set of integrated existing methods and tools that can support the evaluation of the current conditions of the cities in which the Sustainable Urban Regeneration Model will be implemented.

- Actions design. The objective of this second phase is the definition of the specific interventions or actions that will be undertaken in the city. After the analysis of the information collected in the first phase, it will be proposed a solution according with the expectations about energy savings and costs. This is a decision-making process.

- Implementation. The actions designed in the second phase will be implemented and commissioned, covering all fields involved in this urban transformation. In this phase, the deployment of the monitoring program will be key to allow gather the necessary information for assessing the impact of the intervention in the following phase.

- Assessment. This last phase is in charge of assessing the impact of the interventions following evaluation protocols and using the information gathered during the implementation phase. For this evaluation, the most appropriate KPIs will be selected in order to assess the sustainability and the smartness and some specific parameters as the energy consumption, $\mathrm{CO}_{2}$ emissions reduction, reduction of the journey delays, even the social acceptance of the final users and citizens.

The toolkit of solutions and methods needed to transform cities into smarter and more sustainable ecosystems, and integrated through a Sustainable Urban Regeneration Model, is designed with the capability to be adapted and implemented in a wide range of European Cities, focusing on their specific goals and targets, and the boundary conditions that characterize their environment.

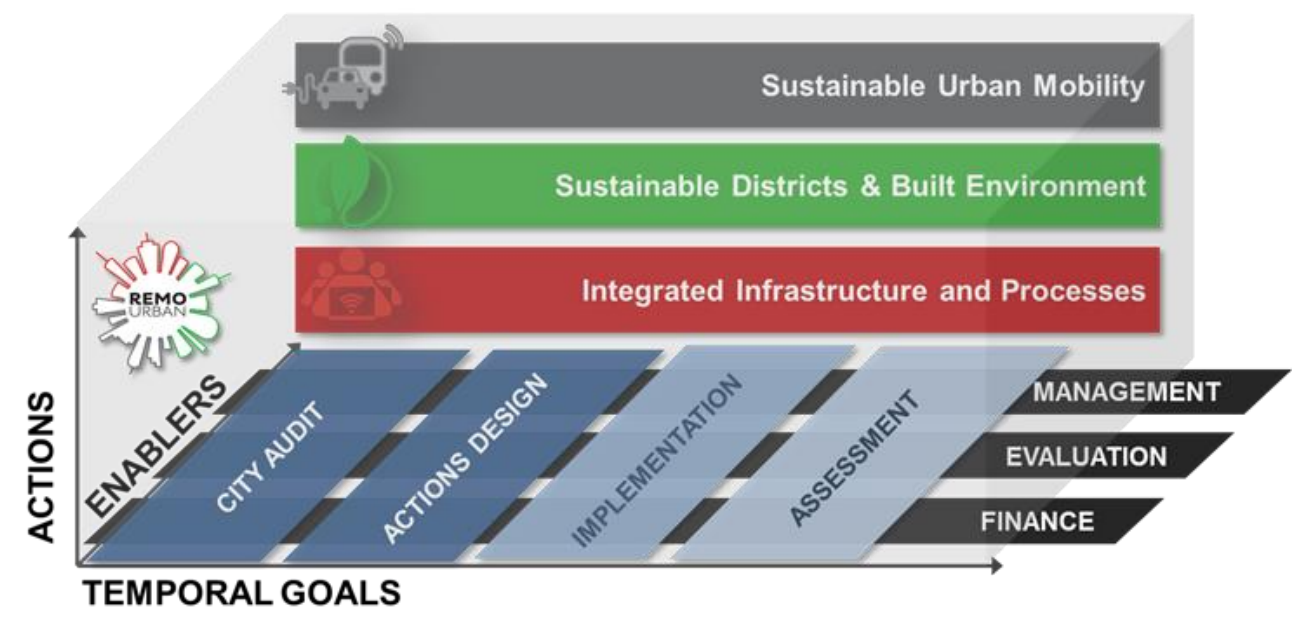

Fig.1. Sustainable Urban Regeneration Model

Source: prepared by the authors

\section{Urban Transformation actions: addressing energy, mobility and infrastructures challenges}


To ensure city transformation is holistic, it is necessary designing multi-sectorial actions that allows achieve more ambitious goals. Most opportunities for city transformation are in energy, mobility and ICT sectors. In fact, it is in the common zone in which these three sectors could act jointly where is possible to find relevant impact.

- Urban districts and built environment. Energy sector, considering the energy supply, distribution and use (mainly in buildings) is a sector with a big impact in city sustainability. A set of actions focused on increasing the overall energy efficiency of a residential district will be developed encompassing the retrofitting of a residential area towards a low energy district, the installation and connection of the heating and cooling systems to a centralized one with a high ratio of generation with renewable energy and the use of advances building energy management systems to automatically monitor and control the main facilities, devices and services at district level.

- Urban transport. Taking into account the mobility sector has a very important impact on quality of life, some sustainability mobility actions will be carried out in order to create a new culture of urban transport. In this field, the use of cleaner vehicles will be promoted and clean power for transport will be improved using electric or hybrid vehicles and charging infrastructure. The logistics supply chain inside cities (last mile delivery) will be enhanced and alliances that use open data will be supported to ease the deployment of demand-responsive and integrated mobility services which help minimize energy consumption.

- Integrated infrastructures and processes. By taking advantage from the ICT sector that is fully integrated in cities, a platform to integrate information and deploying added value services for the grid management and traffic systems will be deployed. ICT sector will enable the deployment of integration strategies of the urban infrastructures with a variety of targets, for instance empowering people to interact with infrastructures, enabling people to become a sensor within overall city infrastructure systems through mobile devices as ubiquitous means, enabling business cases based on the integration of a city's network infrastructures.

In the project, each city will use its own Local ICT platform with the main goal of monitoring all the devices exiting in the city for the project and a Global ICT platform will be used to consolidate the data from these local ICT platforms. Due to the key goal of the REMOURBAN project being its replicability to other cities, a platform with a common model is needed which defines and manages a set of parameters and indicators for assessing the success of the project. This platform is the city integrated infrastructure and this city integrated infrastructure will be created and deployed in the Global ICT platform.

\section{Urban transformation enablers: managing, evaluating and financing the Smart City}

- Management framework for the urban regeneration. It is necessary to optimise the current regulatory framework developing new forms of smart city policies and regulation or optimizing of the existing documents. Moreover, a strategy will be developed for innovative public procurement procedures.

Aspects such as human and social capital, equity, diversity, accessibility, safety, health or quality of housing and the built environment will be taken into account. These will be considered when defining city transformation strategies and designing specific actions, as well as when assessing the achievement of goals at the end of the process. Development of new strategies for favouring the transition to Smart Cities, integrating existing urban plans and redefine them in a common and unique sustainable urban plan (mobility, energy, ICT,..), that would implement a holistic strategy with the objective to transform the city and to make it smarter. 


\section{The International Journal}

ENTREPRENEURSHIP AND SUSTAINABILITY ISSUES

ISSN 2345-0282 (online) http://jssidoi.org/jesi/

2017 Volume 4 Number 3 (March)

- Evaluating the urban regeneration. An evaluation framework is defined in order to assess the sustainability and smartness of demonstration cities involved in the project. This framework allows estimating the effect of the urban regeneration model and the intervention plans for the demonstration cities. Monitoring and evaluation procedures allow quantifying the actual impact of the renovations in order to reduce investment risks, improve the benefits perception and favor the replicability.

- Financing the urban regeneration. Understanding the current status of the city economic ecosystem is essential to define find out suitable economic models for the city transformation, in which a combination of innovative schemes of Public Private Partnerships can be drivers for the implementation of the model. Smart Cities require large amounts of investment to be realised and capital invested in this sector will likely grow every year for decades. Several financial instruments are necessary in order to support these investments. Some financial schemes are already available to stimulate investments in smart cities and, more generally, energy efficiency projects. In this field, innovative financial schemes and business plans for each of the pillars of the project will be developed in order to get that most of the possible interventions can be feasible.

\section{Validation of the urban regeneration model}

The Urban Regeneration Model is being validated in two phases, consisting the first one consists in a large scale demonstration strategy of the potential that the proposed model offers for urban regeneration to deploy integral actions in the areas where energy, mobility and ICT sectors are intimately linked. In particular, the retrofitting of an existing district for reducing energy demand to very low values, improving the generation facilities and the supply of energy for a better use of the local resources (use of renewables) and higher efficiency (use of district scale systems), in order to achieve low energy districts (renewable district heating and cooling, PV, CHP, ...), substitute a high number of conventional vehicles by clean vehicles, improving in parallel the associated infrastructures and the management (for instance electrical vehicles and charging infrastructure) and finally improving through ICT solutions the management of some of the city infrastructures, as the smart grids or the traffic management systems. Moreover, a financial and feasibility plan has been developed in order to guarantee the investments and the return of them. The lighthouse cities also commit the deployment of a powerful monitoring system, in order to gather the necessary variables for the evaluation procedure that is being designed. Further that the technical actions, these interventions will include a relevant citizen engagement activity for maximizing the impact and achieve a wider validation.

The second phase consists in ensuring the model replicability. REMOURBAN has involved from the very beginning other two cities as followers, Seraing and Miskolc, whose mission is twofold: they will ensure that a greater number of use cases are represented in the designing phase, and that the model is properly developed and it is usable even to address some very specific aspects of the cities.

\section{Large scale demonstration in three lighthouse cities}

The deployment and validation of the sustainable urban regeneration model is being carried out through three large scale demonstrations in the aforementioned three lighthouse cities, which are committed to deploy very ambitious holistic interventions, well balanced in terms of actions on energy, mobility and ICTs, that will be fully monitored and properly assessed.

The first demonstration is being carried out in Valladolid (309,000 inhabitants), a medium-size city located in Spain. The demonstration aims at the reduction of $50 \%$ of the energy consumed and $80 \%$ of the $\mathrm{CO}_{2}$ emissions, and involves actively more than 5,700 citizens. The demonstration consists on the renovation of 398 dwellings 
(total 24,600 $\mathrm{m}^{2}$ ), the implementation of renewable energy in the district heating system, the deployment of 45 electrical vehicles, 5 electrical buses and improvement of the charging infrastructure, as well as the development of a city information platform for energy demand management.

The second intervention is taking place at Nottingham (306,000 inhabitants), located in central UK. The target of energy consumption reduction is estimated to be $50 \%$, achieving $26 \%$ of reduction in terms of $\mathrm{CO}_{2}$ emissions. More than 8,100 citizens will be involved actively. The demonstration consists on a deep renovation of 624 dwelling (total $26,823 \mathrm{~m}^{2}$ ), the deployment of 13 new electrical buses and the deployment of an e-Bus charging site, deploying a city information platform for traffic management.

The third intervention is located at Tepebasi (314,599 inhabitants), a municipality of the Eskisehir city, located in Turkey. The demonstration aims at the reduction of $85 \%$ in the energy consumption, and a $79 \%$ of the $\mathrm{CO}_{2}$ emissions. At least 600 citizens will be directly involved in the demonstration, in which 57 dwellings $\left(40,570 \mathrm{~m}^{2}\right)$ will be retrofitted, a district heating/cooling facility based on biomass will be installed, and 11 hybrid vehicles will be used, in addition to a 50 e-bike rental system. An ICT city management platform will be developed in order to put together all energy and mobility data.

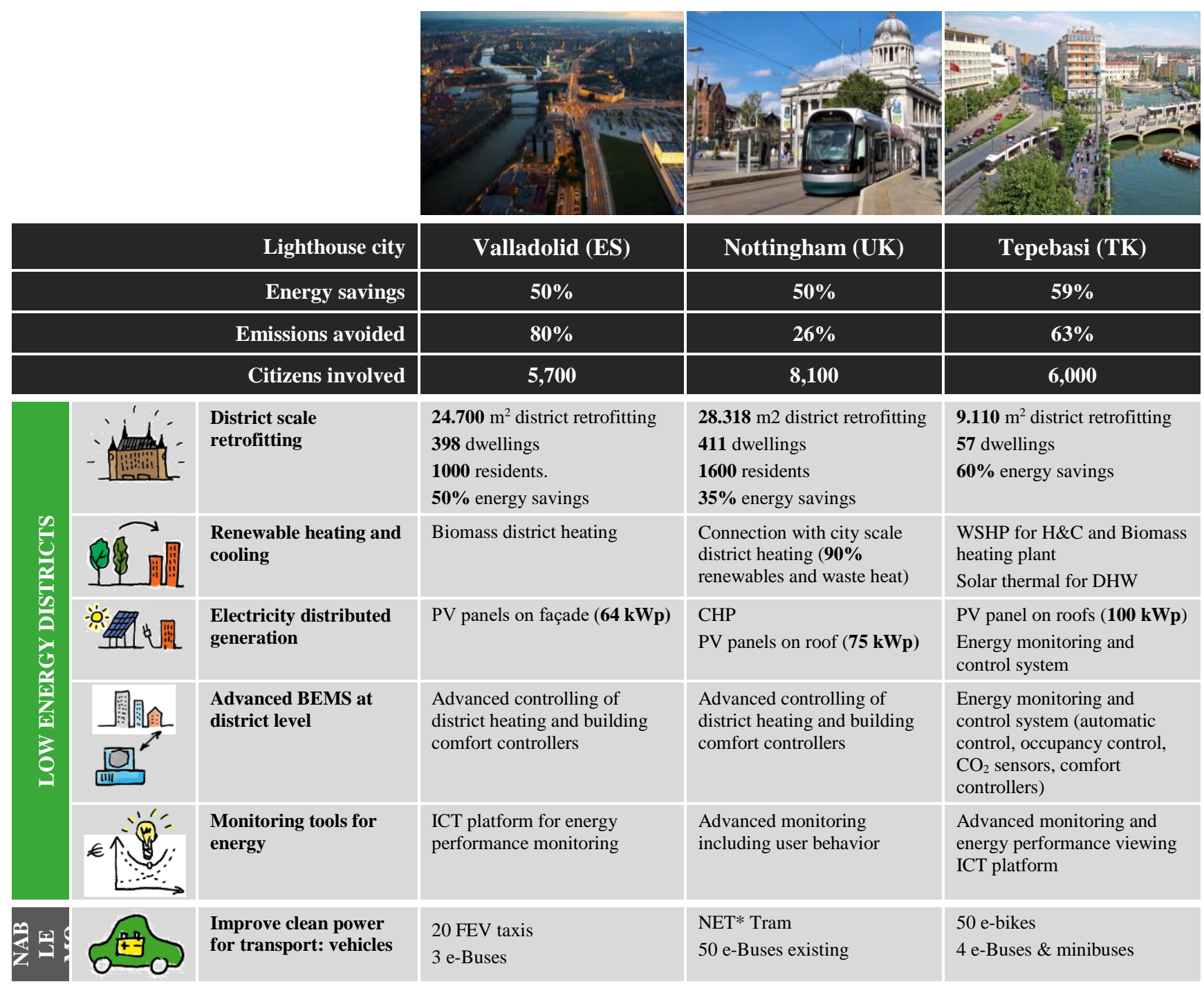


The International Journal

ENTREPRENEURSHIP AND SUSTAINABILITY ISSUES

ISSN 2345-0282 (online) http://jssidoi.org/jesi/ 2017 Volume 4 Number 3 (March)

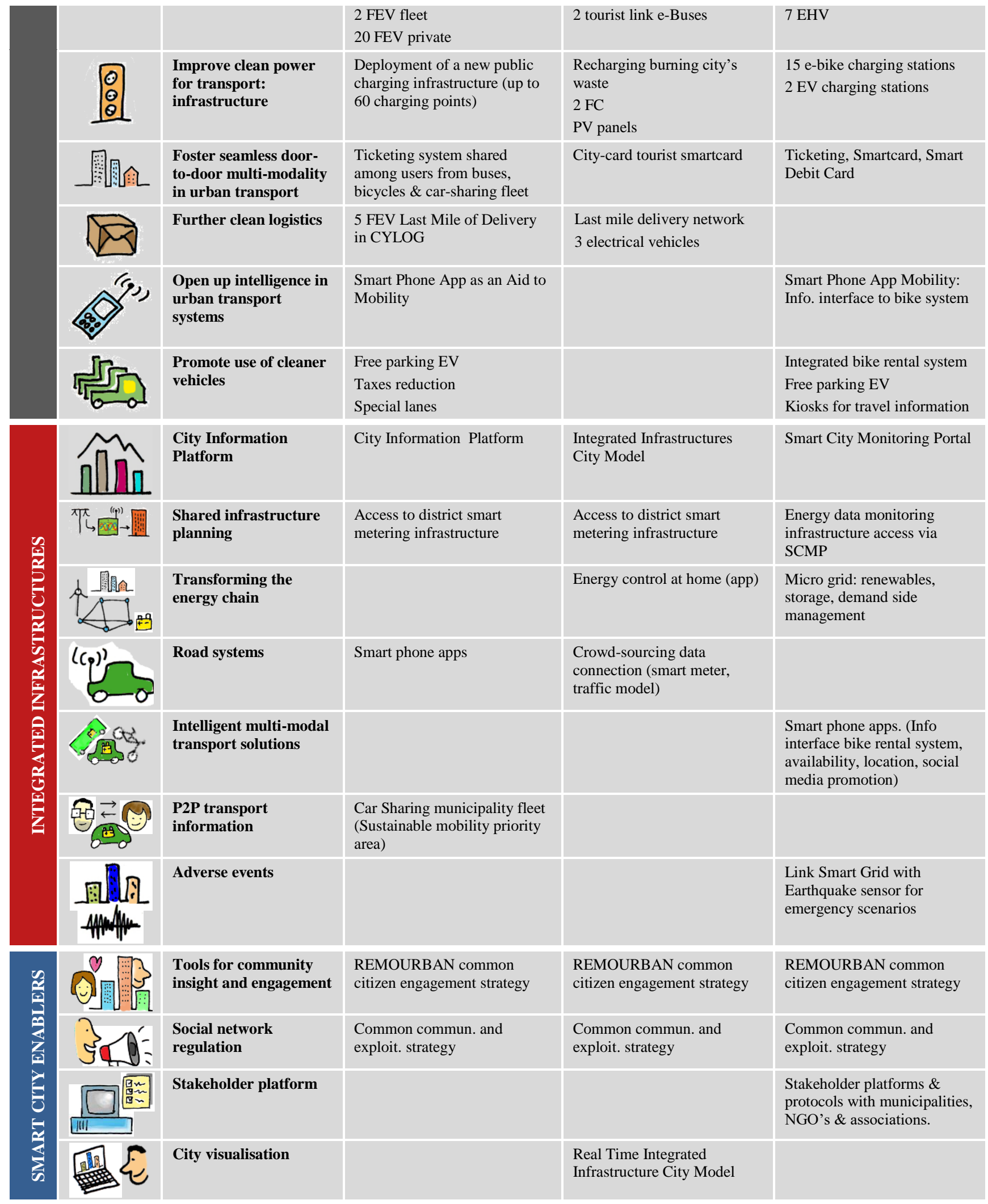


The International Journal

ENTREPRENEURSHIP AND SUSTAINABILITY ISSUES

ISSN 2345-0282 (online) http://jssidoi.org/jesi/ 2017 Volume 4 Number 3 (March)

\begin{tabular}{|c|c|c|c|c|}
\hline$\underset{20102020}{1}$ & $\begin{array}{l}\text { Smart city strategy and } \\
\text { implementation plan }\end{array}$ & $\begin{array}{l}\text { REMOURBAN common } \\
\text { strategy for development of } \\
\text { integrated urban plan }\end{array}$ & $\begin{array}{l}\text { REMOURBAN common } \\
\text { strategy for development of } \\
\text { integrated urban plan }\end{array}$ & $\begin{array}{l}\text { REMOURBAN common } \\
\text { strategy for development of } \\
\text { integrated urban plan }\end{array}$ \\
\hline & $\begin{array}{l}\text { Innovative funding } \\
\text { models }\end{array}$ & $\begin{array}{l}\text { Retrofitting of buildings } \\
\text { adopts an innovative strategy } \\
\text { for multi-owner property } \\
\text { districts }\end{array}$ & $\begin{array}{l}\text { Help private owners of } \\
\text { retrofitted properties }\end{array}$ & \\
\hline & Smart energy map & & $\begin{array}{l}\text { Create a real time energy map } \\
\text { in the demo area. }\end{array}$ & \\
\hline & $\begin{array}{l}\text { EU smart city indicator } \\
\text { framework }\end{array}$ & $\begin{array}{l}\text { REMOURBAN common } \\
\text { sustainable and smartness } \\
\text { evaluation procedure }\end{array}$ & $\begin{array}{l}\text { REMOURBAN common } \\
\text { sustainable and smartness } \\
\text { evaluation procedure }\end{array}$ & $\begin{array}{l}\text { REMOURBAN common } \\
\text { sustainable and smartness } \\
\text { evaluation procedure }\end{array}$ \\
\hline
\end{tabular}

Fig.2. Technical and non-technical actions under implementation in the lighthouse cities

Source: prepared by the authors

\section{Replicability plan}

REMOURBAN aims at not only implementing this model in the three lighthouse cities where the main benefits and suitability of the model will be tested and demonstrate its replication potential and ability to be adapted to these different conditions. A first replication stage will be tested in the follower cities of Seraing (Belgium) and Miskolc (Hungary); but also a wider replicability plan to European Cities is being defined and will be validated.

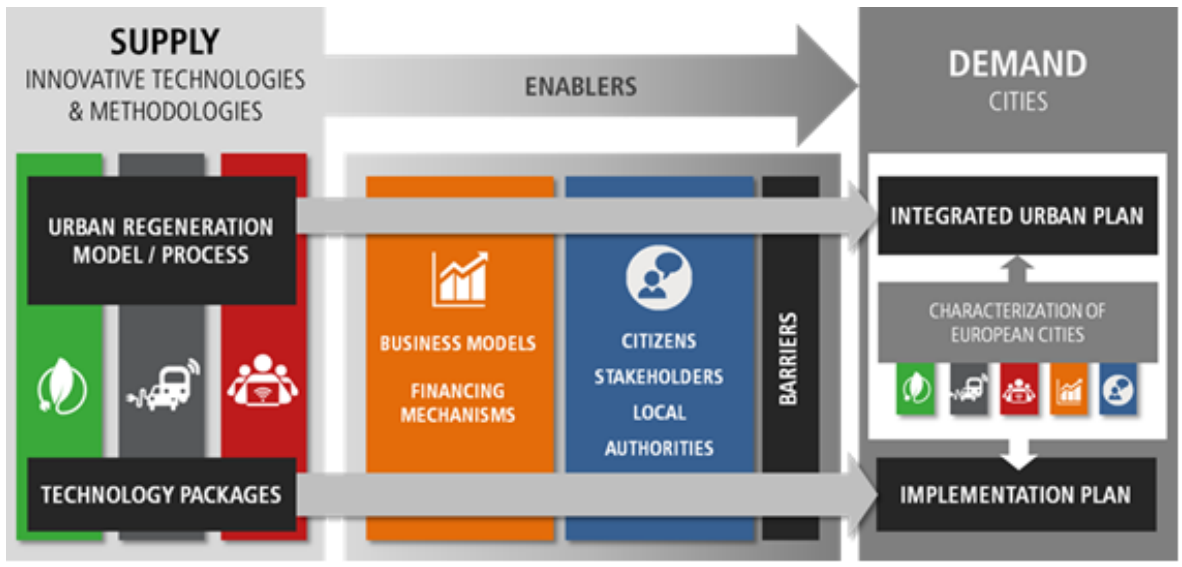

Fig.3. Overall replication strategy approach

Source: prepared by the authors

This replicability plan is based on the characterisation of the European Cities, and grouping of them into specific target areas according to a set of indicators in the main fields of work of this model. The analysis performed in the characterisation of European Cities represents the demand side for urban transformation strategies, it can be connected with the supply side which is able to provide the proper methods and processes, and technology packages to transform the city into a more sustainable and smarter ecosystem. For this, it has to be linked through the proper enablers that make possible its implementation, mainly focused on the finance and governance aspects 
which are able to lead the transformation approach. This necessarily needs to be accompanied by an in-deep analysis of the existing barriers that block the implementation of both the methods and technologies.

This replicability framework is dealing with this connection through integrating all the pieces of the Sustainable Urban Regeneration Model in a single approach, establishing two ways of linkage that lead to the definition of Integrated Urban Plans for the cities and the related Implementation Plans. Thus, the replication of methods and processes can lead to these strategic plans at city level which should establish the long-term approaches needed in the city to ensure the effectiveness of the transformation strategy, while the implementation of the technical solutions can catalyse the integrated city plan into real interventions leading to achieve the macro-level objectives.

\section{Expected impact}

The main challenge is to reduce the impact of the city daily activities of the citizens in the major indicators. These achievements can be summarized as follow:

- Reduction of the human activities impact in the cities at least 5\%, in terms of $\mathrm{CO}_{2} /$ person $\cdot \mathrm{yr}$ emissions and $\mathrm{kWh} /$ person $\cdot \mathrm{yr}$ of energy consumption, by means of the achievement of the following partial objectives:

- Reducing the building energy demand at least a 40\%, with respect to the current consumption to implement zero emission facilities for thermal energy production and increase to a $30 \%$ the distributed electricity generation ratio. Increase the thermal and electrical energy distribution and use efficiency at least a $10 \%$, through public and private investment with a return of the investment less than 15 years in the building retrofitting case and 5 years in case of energy supply interventions.

- Increasing the low carbon mobility solutions a 5\%, 25\% at medium term (5 years). That means a reduction of $\mathrm{CO}_{2}$ emissions of at least a 50\%. Reduction, by means of improvements in the transport management (intermodality...) the average journey delay and door to door journey time a $10 \%$.

- Increase the citizen awareness about the impact of their activities in the city, through an innovative strategy of citizen engagement, which will achieve a reduction of a $10 \%$ of the emissions and energy consumption per capita.

\section{Conclusions}

REMOURBAN project will allow demonstrating that, by means of improving the current conditions of a city, it is possible to achieve low energy districts and more sustainable urban transport, as well as to perceive a greater quality of life. REMOURBAN, thus, will focus on improving the energy efficiency, reduction of GHG emissions, refurbishment of districts, transport sustainability, access to urban information and citizen engagement.

A big impact across Europe will be achieved by the REMOURBAN project results at European level, showing the model for sustainable urban regeneration can be easily applied and replicated. With the aim at maximizing the impact of the project results, REMOURBAN is deploying a powerful communication and dissemination plan that integrates a citizen engagement strategy and disseminates the benefits of the project to a wide variety of audiences. In addition, several exploitation and market deployment strategies will support the commercial exploitation of the sustainable urban regeneration model and other project outcomes. 


\section{References}

Alimo-Metcalfe, B. and Alban-Metcalfe, J. 2008. Engaging Leadership: Creating organisations that maximise the potential of their people, CIPD, London, UK

Branten, E.; Purju, A. 2015. Cooperation projects between university and companies: process of formation and objectives of the stakeholders, Entrepreneurship and Sustainability Issues 3(2): 149-156. DOI: http://dx.doi.org/10.9770/jesi.2015.3.2(3)

Chaffey, D., (2010). Applying organisational capability models to assess the maturity of digital-marketing governance, Journal of Marketing Management, 26(3-4), pp. 187-196.

Collins, J. and Hansen, M. 2011. Great By Choice, Harper Business, New York, USA

Estampe, D., Lamouri, S., Paris, J.L. and Brahim-Djelloul, S. 2013. A framework for analysing supply chain performance evaluation models, International Journal of Production Economics, 142(2), 247-258

EU Regional Policy, State of European Cities Report- Adding value to the European Urban Audit, May 2007, Available at http://ec.europa.eu/regional_policy/sources/docgener/studies/pdf/urban/stateofcities_2007.pdf [Accessed 10 January 2017]

European Smart cities ranking by Vienna University of Technology. Available at <http://www.smart-cities.eu/> [Accessed 10 January 2017]

EUROSTAT website http://ec.europa.eu/eurostat/web/main/home [Accessed 10 January 2017]

Market Place of the European Innovation Partnership on Smart Cities and Communities - EU projects page https://eu-smartcities.eu/euprojects [Accessed 10 January 2017]

Munro, J. 2015. Accelerating innovation in local government, Public Money \& Management, 35(3): 219-226. http://dx.doi.org/10.9770/10.1080/09540962.2015.1027498

Ngai, E.W.T., Chau, D.C.K., Poon, J.K.L. and To, C.K.M. 2013. Energy and utility management maturity model for sustainable manufacturing process, International Journal of Production Economics, 146, 453-464.

PLEEC - Rudolf Giffinger, G. H. January 2014. Typology of cities - WP2 - Deliverable 2.2. Vienna: TUWIEN Team.

REMOURBAN website http://www.remourban.eu [Accessed 10 January 2017]

Rheinisch-Westfälisches Institut für Wirtschaftsforschung. November 2010. Second State of European Cities Report. Research Project for the European Commission, DG Regional Policy. Essen, Germany: Policy Research \& Consultancy - PRAC

\section{Aknowledgements}

This research was supported by the project, which has received funding from the European Union's Horizon 2020 research and innovation programme under the grant agreement No 646511.

The article reflects the views only of the authors, and the Commission cannot be held responsible for any use which may be made of the information contained therein. The information in this document is provided as is and no guarantee or warranty is given that the information is fit for any particular purpose. The user thereof uses the information at its sole risk and liability

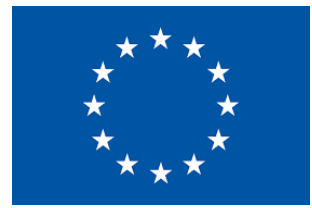


The International Journal

ENTREPRENEURSHIP AND SUSTAINABILITY ISSUES

ISSN 2345-0282 (online) http://jssidoi.org/jesi/

2017 Volume 4 Number 3 (March)

\section{Authors:}

Miguel Á. GARCÍA-FUENTES. B.Arch. (2010) and MSc Arch. (2012), from the Valladolid University (Spain). Working as European Projects' Coordinator at the Energy Division of CARTIF Technology Centre in European RTD Projects in the framework of Smart Cities and Nearly Zero Energy Cities, he currently coordinates REMOURBAN and OptEEmAL EU-H2020 funded projects. He has contributed to various national and international relevant congresses related to sustainability and energy efficiency in building. Recently, he has been appointed as member of the Special Interest Group (Advisory Council) of the FP7 funded project OPTIMUS and as member of the Technical Committee for the 3rd Spanish Congress on NZEB.

ORCID ID: orcid.org/0000-0001-6739-599X

Cristina DE TORRE. Industrial Engineer (2006) and MSc. Eng. in Energy Engineering (2010), both from the University of Valladolid (Spain). Working as researcher and Head of Projects at CARTIF's Energy Division. Along her work career at CARTIF, she has been involved on many National and European Projects linked mainly on integration of renewable energies in buildings, energy performance simulation, buildings energy refurbishment, energy audit, monitoring and control of solar thermal heating and cooling installations and low energy buildings. She has contributed to different congresses of national and international relevance related to renewable energies and energy efficiency.

ORCID ID: orcid.org/0000-0002-7609-5099

Copyright (C) 2016 by author(s) and VsI Entrepreneurship and Sustainability Center

This work is licensed under the Creative Commons Attribution International License (CC BY).

http://creativecommons.org/licenses/by/4.0/

C) (i) Open Access 